\title{
Global Environmental Pollution and Coronavirus
}

\author{
M. A. Quader ${ }^{1}$ \\ ${ }^{1}$ Distinguished Faculty, Asian Institute of Technology, Bangkok, Thailand \\ Correspondence: M. A. Quader, Distinguished Faculty, Asian Institute of Technology, Bangkok, Thailand. E-mail: \\ quader43@gmail.com
}

Received: August 9, 2020

Accepted: September 18, 2020

Online Published: September 28, 2020

doi:10.5539/ep.v9n2p19

URL: https://doi.org/10.5539/ep.v9n2p19

\begin{abstract}
Discussions, analyses and modelling are based on global level data. The natural environment is causing deaths to its habitants. The ongoing coronavirus is also doing damage to the lives of the glove. Worldwide people are too much worried putting extra ordinary efforts to contain the coronavirus pandemic. But the damage being done to the lives of the people on the glove by natural environment problems is substantially higher than that done by the coronavirus. Air pollution death rate is 6.02 times of death rate due to coronavirus and the total environmental death rate is 10.85 times that of coronavirus death rate.
\end{abstract}

Three statistical models regarding coronavirus development, coronavirus spread and coronavirus fatality are developed.

\section{Research Purpose}

We are passing in very hard days where the mother nature seems to be trying to take revenge against the human society for disobeying the nature. It is really the environmental problems that are at the root. We are overloading the nature by our manmade environmental works. Air pollution is the single most factor causing the biggest problem. Air pollution is causing immense suffering to human beings. The present happenings also stem from air pollution primarily.

Environment intermingles with our life. We live in the natural environment formed by air, water and the living surrounding. The Coronavirus is now affecting all the natural surroundings and hence our lives.

Our living atmosphere faces the day to day usual surrounding and now with additional burden of coronavirus. A review needs to be made as to the effect of natural environment and the coronavirus.

In the context of the ongoing coronavirus that is devastating the world, the purpose of this research is as follows:

(a) Review of the global situations of environmental problems and Coronavirus. The problems are not generally understood clearly.

(b) Develop some Coronavirus Models.

\section{Review of Literature}

The coronavirus phenomenon is rolling over the globe. This has engulfed the entire world within a very short time. Corona has been defined as the phenomenon of ionisation of surrounding air around the conductor due to which luminous glow with hissing noise is rising that is known as the corona effect. Air acts as a dielectric medium between the transmission lines. In other words, it is an insulator between the current carrying conductors. Its special feature is that its clinical identity has not yet been identified and no medication is yet available. Scientists are trying hard to do the job. The only remedy available is social distancing.

Environmental damage is taking a great toll on the people of the world. Scientists have become up and doing a lot to contain the epidemic and recover the damage. Their efforts brought some results to some extent.

This result is reflected in the following table (Table 01). Death rates are per 100,000 population. 
Table 1. Improvement of death rates globally

\begin{tabular}{ccccc}
\hline Item & $\begin{array}{c}\text { Death Rate/ Year } \\
\text { in 1990 }\end{array}$ & $\begin{array}{c}\text { Death Rate/ Year } \\
\text { in } 2017\end{array}$ & $\begin{array}{c}\text { Death Rate Improved } \\
\text { per Year }\end{array}$ & $\begin{array}{c}\text { Remark: } \\
\text { Results are } \\
\text { global. }\end{array}$ \\
\hline $\begin{array}{c}\text { Air Pollution (Total) } \\
\text { Indoor Pollution }\end{array}$ & 111.28 & 63.82 & 1.76 & Fastest \\
$\begin{array}{c}\text { Outdoor Particulate } \\
\text { Matter }\end{array}$ & 61.11 & 39.15 & 0.81 & \\
$\begin{array}{c}\text { Outdoor Ozone } \\
\text { Pollution }\end{array}$ & 43.68 & 38.16 & 0.20 & Slowest \\
\hline
\end{tabular}

Source: Calculated by the author.

All figures are global. Improvement took place in all items. More need to be done. World over environmental damages outweighs the improvement.

Spanish Flu engulfed the world in three waves, 1918, 1919 and 1920. The pandemic unlike coronavirus is confirmed to be influenza with virus strain of A/H1N1. Its outbreaks continued from February to April 1920. Estimated 500 million people were inflicted with estimated deaths of $17-50+$ million people.

\section{The Environment}

The word environment means surroundings, in which organisms live. Environment and the organisms are two dynamic and complex components of nature. Environment regulates the life of the organisms including human beings. Human beings interact with the environment more vigorously than other living beings. Ordinarily environment refers to the materials and forces that surrounds the living organism, here human lives. Coronavirus is being developed in and from the environment and is naturally related to it.

Major components of the environment include - Natural Components like, Land (Lithosphere), Water (Hydrosphere), Air (Atmosphere), and Living things (Organism). Human made Components like, buildings, parks, bridge, road, industries etc. Humans include like individuals, family, community, religion, politics, education.

\subsection{Environmental Factors}

Examples of environmental factors include soil, water, climate, natural vegetation and land forms. Environmental factors entail everything that changes the environment. Some factors are visible, while others cannot be seen. In some situations, only the effects of environmental changes are evident. Some environmental factors that affect health are exposure to hazardous substances in the air, water, soil, and food. and the built environment.

Environmental Health is Important. Maintaining a healthy environment is central to increasing quality of life and years of healthy life. Globally, $23 \%$ of all deaths and $26 \%$ of deaths among children under age 5 are due to preventable environmental factors. Environmental factors are diverse and far reaching.

Poor environmental quality has its greatest impact on people whose health status is already at risk. Therefore, environmental health must address the societal and environmental factors that increase the likelihood of exposure and disease.

Some of the big Environmental Threats/Problems are climate, air and water pollution.

\subsection{Coronavirus is Changing the Environment}

Coronavirus is set to leave a vast imprint in the world, and that includes on its environment. These include

1) Improvements in air quality

2) Greenhouse gas emissions

3) Mountains of waste

- With many factories and businesses closed, combined with fewer cars on the road and fewer planes in the sky, our natural environment is recovering slowly.

- China's $40 \%$ drop in $\mathrm{NO}_{2}$ on 2019 levels for January and February in some areas equates to removing a whopping 192,000 cars. 
The COVID-19 pandemic has caused industrial activity to shut down and cancelled flights and other journeys, slashing greenhouse gas emissions and air pollution around the world. If there is something positive to take from this terrible crisis, it could be that it has offered a taste of the air we might breathe in a low-carbon future.

The World Health Organization (WHO) estimates that about 3 million people die each year from ailments caused by air pollution, and that more than $80 \%$ of people living in urban areas are exposed to air quality levels that exceed safe limits. The situation is worse in low-income countries, where $98 \%$ of cities fail to meet WHO air quality standards.

Measurements from the European Space Agency's Sentinel-5P satellite show that during late January and early February 2020, levels of nitrogen dioxide $\left(\mathrm{NO}_{2}\right)$ over cities and industrial areas in Asia and Europe were lower than in the same period in 2019 , by as much as $40 \%$.

\subsection{Coronavirus Coverage}

- $\quad$ IEA: Coronavirus impact on CO2 emissions six times larger than 2008 financial crisis

- Analysis: Coronavirus has cut CO2 from Europe's electricity system by 39\%

- Analysis: Great Britain hits coal-free electricity record amid coronavirus lockdown

- $\quad$ Analysis: Coronavirus set to cause largest ever annual fall in CO2 emissions

- Coronavirus: What could lifestyle changes mean for tackling climate change?

- Analysis: Coronavirus temporarily reduced China's $\mathrm{CO} 2$ emissions by a quarter

- Leading economists: Green coronavirus recovery also better for economy

\subsection{Corona Spread}

The COVID-19 virus, popularly termed as Corona, is transmitted from one person to another through air, if normally about one meter or less apart. If the patient speaks louder, the virus can travel further distance.

The Earth rotates from west to east or counter-clockwise.

The earth rotates from west to east in its daily orbit. The air surrounds the earth and is caused to rotate.

Wind's reaction near earth surface is east to west. So, its pollution load direction is east to west. That is the reason the Corona virus is acting/moving from east to west. It is moving from China to USA, not otherwise.

The direction of Coronavirus travel is shown in the following diagram (Fig 01).

\begin{tabular}{|l|l|l|l|l|l|}
\hline $\begin{array}{l}\text { The Direction of } \\
\text { Countries }\end{array}$ & Countries & Corona Starts Date & $\begin{array}{l}\text { Direction Cona } \\
\text { Travelled }\end{array}$ \\
\hline & & China & January 22 & & \\
\hline & India & March 04 & & \\
\hline & Iran & February 25 & & \\
\hline & UK & March 15 & & \\
\hline & Saudi Arabia & March 11 & & \\
\hline & Sudan & March 18 & & \\
\hline & Algeria & March 03 & & \\
\hline & Canada & March 10 & & \\
\hline & Australia & March 03 & & \\
\hline & Brazil & March 13 & March 13 & \\
\hline
\end{tabular}

Figure 1. Direction of coronavirus travel

\subsection{Air Pollution}

Air pollution is the world's largest single environmental health risk. Air pollution contributes to $9 \%$ of deaths globally - this varies from $2 \%$ to $15 \%$ by country 
Outdoor air pollution alone causes deaths annually of 5,753 to 11,534 persons/day. Overall, outdoor and indoor, air pollution causes the deaths of around 19,178 persons/day worldwide, and is the world's largest single environmental health risk.

As per estimate of USEPA (US Environmental Protection Agency), air pollution globally causes deaths of 13,699 people/day.

USEPA Summarizes effect of air pollution as follows:

Air pollution is one of the world's leading risk factors for death, attributed to 5 million deaths each year ${ }^{[04]}$.

- $\quad$ Air pollution is attributed to $9 \%$ of deaths globally.

- It is also one of the leading risk factors for disease burden.

- Death rates from air pollution are highest in low-to-middle income countries, with more than 100 -fold differences in rates across the world.

- Globally, death rates from air pollution have been falling. This has mainly been the result of progress on tackling indoor pollution.

The global summary information is shown in the following table (Table 02).

Table 2. The environmental and air pollution facts

\begin{tabular}{|c|c|c|c|}
\hline Sl. No & Factor & Unit & Figure \\
\hline $1 \mathrm{a}$ & Outdoor Air Pollution Deaths & persons/ day & 5,753 to 11,534 \\
\hline $1 \mathrm{~b}$ & Overall Air Pollution Deaths & Persons/ day & 19,178 \\
\hline $2 \mathrm{EPA}$ & Air Pollution Death & Persons/ day & 13,699 \\
\hline 3 & Air Pollution Death & Persons/ day & 8,219 \\
\hline 4 (WHO) & Total Environment Attributable Deaths & Person/day & 34,588 \\
\hline $5 a$ & $\begin{array}{l}\text { Corona Cases Globally (average } \\
(22.01 .20-30.06 .20)\end{array}$ & Persons/ day (average) & 65,016 \\
\hline $5 b$ & $\begin{array}{l}\text { Corona Deaths Globally (average } \\
22.01 .20-30.06 .20 \text { ) }\end{array}$ & Persons/day (average) & 3,188 \\
\hline
\end{tabular}

Source: compiled by author

According to estimate of WHO, we can see that 19,178 deaths are occurring per day on average globally due to air pollution (indoor and outdoor). The average per day number of person deaths in case of coronavirus is only 3,188 . However, corona cases are 65,016 per day on average. It has created pandemic world over. It has caused over saturation of the atmosphere with environmental problems.

It seems surprising that not much serious attention has been given by the world on the issue of gradual degradation of the environment. It has not occurred in a day. Degradation of the environment has been occurring for a long time, each day more and more pollutants being added.

The USA has lately taken up the problem by The Clean Air Act of 1,963.

Coming to the air pollution, we know that about a billion tons of the air pollutants are added every year to the previous year figure. Global CO2 produced in 2017 was 1,146.31 ton per second.

The latest pollution numbers, calculated by the Global Carbon Project, a joint venture of the Energy Department and the Norwegian Research Council, show that worldwide carbon dioxide levels are 54 percent higher than the 1990 baseline.

\subsection{Damages to the Environment}

Damages are continuously being done to the environment, more to the air environment. This is being done mostly by burning of fossil fuels. Fossil fuels include coal, petroleum, natural gas, oil shales, bitumens, and heavy oils.

In the modern world, fossil fuel combustion is the biggest contributor to air pollution. The leading culprit today is traffic, but factories and power plants also continue to contribute to some extent. Burning of petrochemicals is also 
in the list.

Fossil fuels are found in almost every product we use daily. One major use of these products is as fuel, gasoline for cars, jet fuel, heating oil and natural gas used to generate electricity.

The primary fossil fuels are coal, petroleum and natural gas. Fossils are mineralized remains of ancient plants and animals. They're our primary way of studying life forms that lived millions of years ago. But actual fossils have nothing to do with any of the fuels.

Petrochemicals are chemical products derived from petroleum, although many of the same chemical compounds are also obtained from other fossil fuels such as coal and natural gas or from renewable sources such as corn, sugar cane, and other types of biomass.

Petrochemical products include plastics, rubbers, resins, synthetic fibers, adhesives, dyes, detergents, pesticides, and petroleum-derived paints and coatings. Petrochemicals are used to manufacture thousands of different products that people use daily, including plastics, medicines, cosmetics, furniture, appliances, electronics, solar power panels, and wind turbines.

Burning of fossil fuels and their derivatives create enormous pollutants in the air. These pollutants have overloaded the air environment. The air seems to have saturated the absorption capacity.

\subsection{Water Pollution}

Some 80 percent of the world's wastewater is dumped, largely untreated, back into the environment, polluting rivers, lakes, and oceans. This widespread problem of water pollution is jeopardizing our health.

This is for information with regard to work that Clean Water Act dramatically cut pollution in US waterways.

Summary of water pollution facts: Most of water pollution measures showed improvement, including an increase in dissolved oxygen concentrations and a decrease in fecal coliform bacteria. The share of rivers safe for fishing increased by twelve percent between 1972 and 2001.

With 1.2 billion people lacking clean water, waterborne infections account for 80 percent of all infectious diseases. Increased water pollution creates breeding grounds for malaria-carrying mosquitoes, killing 3,288 people/day to 7,397 people/day and air pollution kills about 19,178 people/day. Water pollution is an added burden on the environment.

\section{Coronavirus}

What is coronavirus? Coronaviruses are a family of viruses that range from the common cold to MERS coronavirus, which is Middle East Respiratory Syndrome coronavirus and SARs, Severe acute respiratory syndrome coronavirus.

COVID-19 (a specific coronavirus) is the disease caused by the new coronavirus that emerged in China in December 2019. The COVID-19 virus, popularly termed as Corona, is transmitted from one person to another through air, if normally about one meter or less apart. If the patient speaks louder, the virus can travel further distance. On January 31, the first 2 novel coronavirus cases in the UK, the first 2 cases in Russia, and the first case in Sweden and in Spain were reported. Canada reported its $4^{\text {th }}$ case.

What began with a handful of mysterious illnesses in a central China city has traveled the world. First detected on the last day of 2019, the novel coronavirus has killed more than 508,844 (up to June 30, 2020) people with infections surpassing three million worldwide. It has triggered nationwide lockdowns, stock market upheaval and dangerous conspiracy theories.

Most cases are mild, but health officials say much is still unknown about the virus that causes the disease now named covid-19. On 11 February 2020, WHO announced a name for the new coronavirus disease: COVID-19.

\subsection{Global Spread of Coronavirus Cases}

As may be seen from the figure hereafter, Coronavirus is spreading very fast. There is a jump after $70^{\text {th }}$ day. However, the death fatality is increasing in a consistent way.

Situation of Coronavirus globally is shown in the following diagram (Fig 02). 


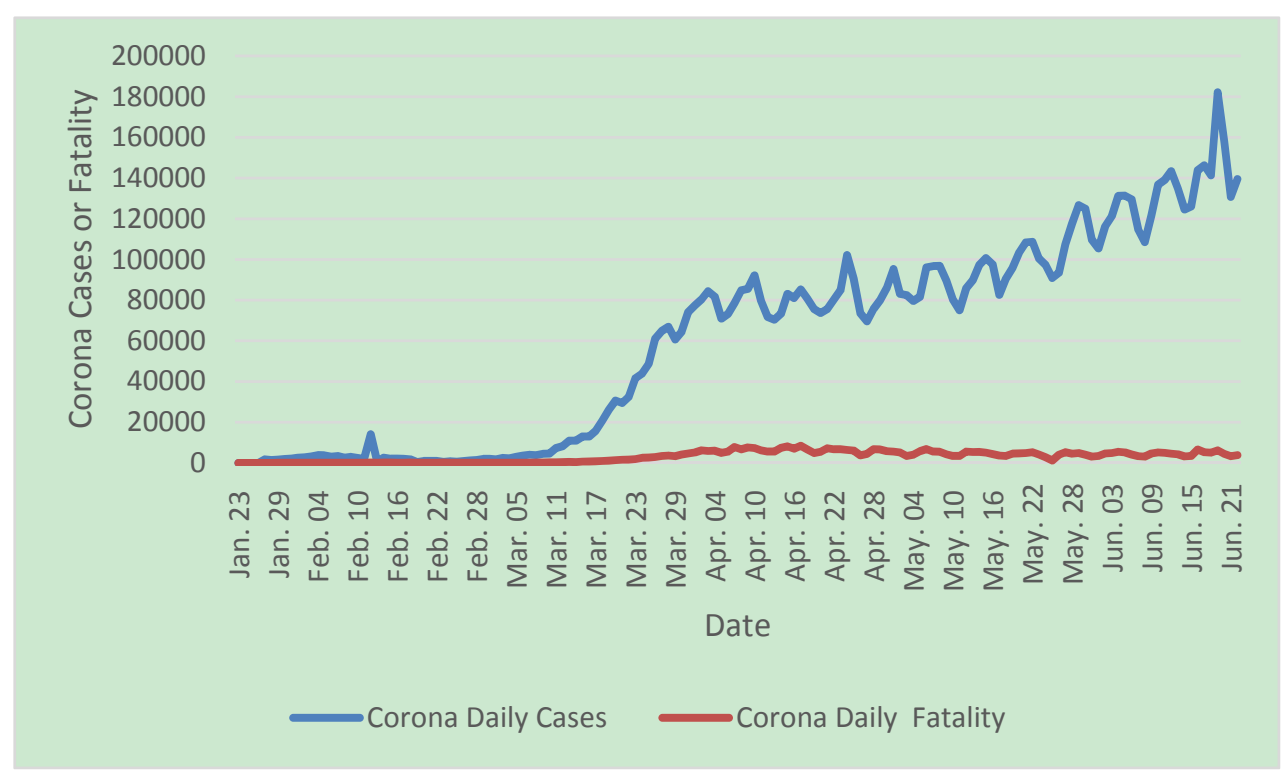

Figure 2. Coronavirus daily cases and fatality global

Source: With figures from Worldometer, drawn by author.

4.2 Situation of Global Coronavirus Cases (Fig 03)

\begin{tabular}{|c|c|c|}
\hline & $\begin{array}{c}\text { Coronavirus Cases } \\
20,254,662\end{array}$ & \\
\hline Active Case & Closed Case & Deaths: \\
\hline $6,397,114$ & $13,857,548$ & $738,930(3.65 \%)$ \\
\hline Currently Infected & $\begin{array}{c}\text { Cases which had an } \\
\text { outcome }\end{array}$ & \\
\hline 64,538 (1\%) & $13,118,618(\mathbf{9 5} \%)$ & Recovered: \\
\hline Serious or & Recovered / & $13,118,618(64.77 \%)$ \\
\hline Critical & Discharged & \\
\hline $6,332,576(\mathbf{9 9} \%)$ & $738,930(5 \%)$ & Others: \\
\hline Mild Condition & Deaths & $6,397,114(31.58 \%)$ \\
\hline
\end{tabular}

Figure 3. Situation of global coronavirus cases as on 11 August 2020

Source: With figures from worldometer, worldometer COVID-19 Data [11] drawn by author

Global situation of Corona infection is shown in the above diagram. One point of note is that Corona is spreading very fast although by number, its intensity of infliction is less than that of natural environmental fatality.

\section{Statistical Coronavirus Model}

The following statistical models are developed using SPSS.

\subsection{Coronavirus Model Regarding Its Development}

Using the cross - sectional data of 99 countries (sample size) and using SPSS, the following statistical model has been developed. The dependent variable is $\mathrm{Y}$ (Total Cases in log scale). There are 5 independent variables as shown 
(X1 to X5). The model is a very efficient one as you can see; the $\mathrm{R}^{2}$ value is $0.9538(95.38 \%)$. Please note that Coronavirus development depends on population, population density, pollution index, environmental performance index and health index.

The model can very well be used for prediction.

$\mathrm{Y}=-1.18229858+8.169643296 \mathrm{X} 1-0.00 \mathrm{te} 0010186 \mathrm{X} 2+0.002841657 \mathrm{X} 3+0.002061826 \mathrm{X} 4+0.139778007 \mathrm{X} 5$

$\mathrm{Y}=$ Total Cases (in log)

$\mathrm{X} 1=$ Population (in log)

$\mathrm{X} 2=$ Population Density (people $/ \mathrm{km}^{2}$ )

$\mathrm{X} 3=$ Pollution Index

$\mathrm{X} 4$ = Environmental Performance Index

$\mathrm{X} 5=$ Health Index

$\mathrm{R}^{2}=0.9538(95.38 \%)$

$\mathrm{n}($ sample size $)=99$ countries

Note: Cross sectional data

\subsection{Coronavirus Model Regarding Its Progression}

The second model developed to predict the coronavirus prediction over time is as follows.

Coronavirus Cases $=-21423.30+1069.16 *$ time

Correlation Coefficient between Corona Cases and time $=0.9563$, very high.

Unit of Corona cases is number; unit of time is day.

$\mathrm{R}^{2}$ value $=0.9145(91.45 \%)$

This model is also very efficient. You can see very high $\mathrm{R}^{2}$ value $(0.9145,91.45 \%)$.

An example may be given here.

On $152^{\text {nd }}$ day (starting day is $23^{\text {rd }}$ January 2020 ), the global corona cases will be as follows:

$-21423.3+1069.16^{*} 152=141,088$. Actually, it was 139,607 .

In order to develop the statistical model, global time series data from 23 January to 28 June 20 were used.

Sample size $\mathrm{n}=152$ days starting from 23 January 2020.

\subsection{Coronavirus Model Regarding Its Fatality}

For development of this third model, global time series data from 23 January to 20 June 2020 were used.

Daily Corona Fatality $($ Death $)=0.320122419+00.513562137 * \log$ case $+0.0061717085 *$ time

Corona fatality in number; corona cases in number; time in day.

$\mathrm{R}^{2}=0.8107(81.07 \%)$

$\mathrm{n}$ (sample size - time series $)=23$ January to 20 June 2020 .

Example:

$$
\begin{aligned}
\text { Fatality } & =0.320122419+0.513562137 * \text { Corona case }+0.0061717085 * \text { time } \\
& =0.320122419+0.513562137 * 5.198002403+0.0061717085 * 150 \\
& =0.320122419+2.669497+0.925755 \\
& =3.9153744 \rightarrow 8,229
\end{aligned}
$$

Note because of high $\mathrm{R}^{2}$ value 0.8107 (81.07\%) the model will be efficient.

\subsection{Prevalence/ Density of Coronavirus in City and Country}

It is hypothesized that Corona Virus is more prevalent in town areas as compared to other areas.

Data from two samples were analyzed with the help of statistical technic. Two samples were chosen. Sample 1: Country area as a whole with sample size of 110 countries. Sample 2 was 703 towns. The variable was Corona density (number of coronavirus cases per million inhabitants). Mean Test was applied (Table 03). 
Table 3. Summary results of statistical tests of two samples

\begin{tabular}{ll}
\hline Sample 1: Country area as a whole & Sample 2: Town areas only \\
\hline Sample size n1: 110 countries & Sample size n2: 703 towns \\
Unit of sample: Density of Corona cases per million & Unit of sample: Density of Corona cases per million \\
inhabitants & inhabitants \\
Sample mean: 927.75 & Sample Mean: 560.65 \\
Sample Standard Deviation: $1,280.57$ & Sample Standard Deviation: $2,490.97$ \\
Significance level $(\alpha=0.05)$ & Significance level $(\alpha=0.05)$ \\
Conclusion: Corona Virus density is less. & Conclusion: Corona Virus density is greater \\
\hline
\end{tabular}

Test statistics $\mathrm{zc}=2.38$ as against critical statistic $\mathrm{zc}=1.55$

Statistical test was applied for the hypothesis. It is found and concluded that the mean density of Coronavirus cases prevalent in town areas is significantly higher. This means that in the Coronavirus cases in town areas and congested areas are more.

\subsection{Social Distance}

Social distancing is a very important variable. But this could not be included in model since there is no quantitative data available on this account.

In a research during Spanish Flu David J Philp and Kevin McCracken observed that the observed clinical attack rate of $36.6 \%$ was substantially lower than the $59 \%$ expected based on the estimated value of $\mathrm{R}_{0}$ (basic reproduction number), implying that approximately $22 \%$ of the population were spared from clinical infection. This reduction in the clinical attack rate translates to an estimated 260 per 100,000 lives having been saved, and suggests that social distancing interventions could play a major role in mitigating the public health impact of future influenza pandemics.

\subsection{Example of Success in St. Louis, Failure in Philadelphia in Social Distancing}

Even though they didn't have the highest or lowest death rates in the country, two major U.S. cities emerged as examples of government response in what to do and what not to do: St. Louis, which recognized the viral danger and took immediate steps to contain it, and Philadelphia, which did not (Fig 05).

There is one example showing the importance of Social Distance. The example is the Spanish Flu. Social Distance there worked wonderful. It might still be one of the best ways of fighting this present pandemic. It might still be one of the best ways of fighting this pandemic.

The death rates in Philadelphia and St Louis during the 1918 Spanish flu pandemic demonstrate the importance of social distancing.

Maintaining Social Distancing rule is sensitive. In UK, Swine Flu effect in 2009 reappeared when one social distancing was not there. Our scientists should not over-rule out such a phenomenon and should remain aware of situation.

Swine flu cases per week in the United Kingdom in 2009; schools typically close for summer in mid-July and reopen in early September.

Among the worst moments of the 1918 influenza pandemic were Philadelphia's overwhelmed morgue stacking un-embalmed bodies without ice on multiple floors until storage was found, or the city resorting to steam shovels for digging mass graves.

The 1918 Spanish influenza - a vicious disease, some historians call it - emerged as World War I was ending. It killed 50 million or more people worldwide, 675,000 in the USA alone.

\section{Conclusion and Recommendation}

Globally, death rate caused by overall air pollution only is 19,178 persons per day on average and that by coronavirus is 3,188 persons per day on average only. The death rate attributable to total environment is 34,588 persons per day.

The coronavirus death rate is only $16.62 \%$ of the air pollution death rate. Total environmental pollution death rate is 34,588 per day and the coronavirus death 3,188 persons per day. The former is 10.85 times of the latter (Fig 04). 
The countries are for the people. Any drastic action necessary to protect the lives of the people will have to be taken. It is very strongly suggested to create a all powerful world body called "Environment Police" to arrange and implement the environmental police work world over.

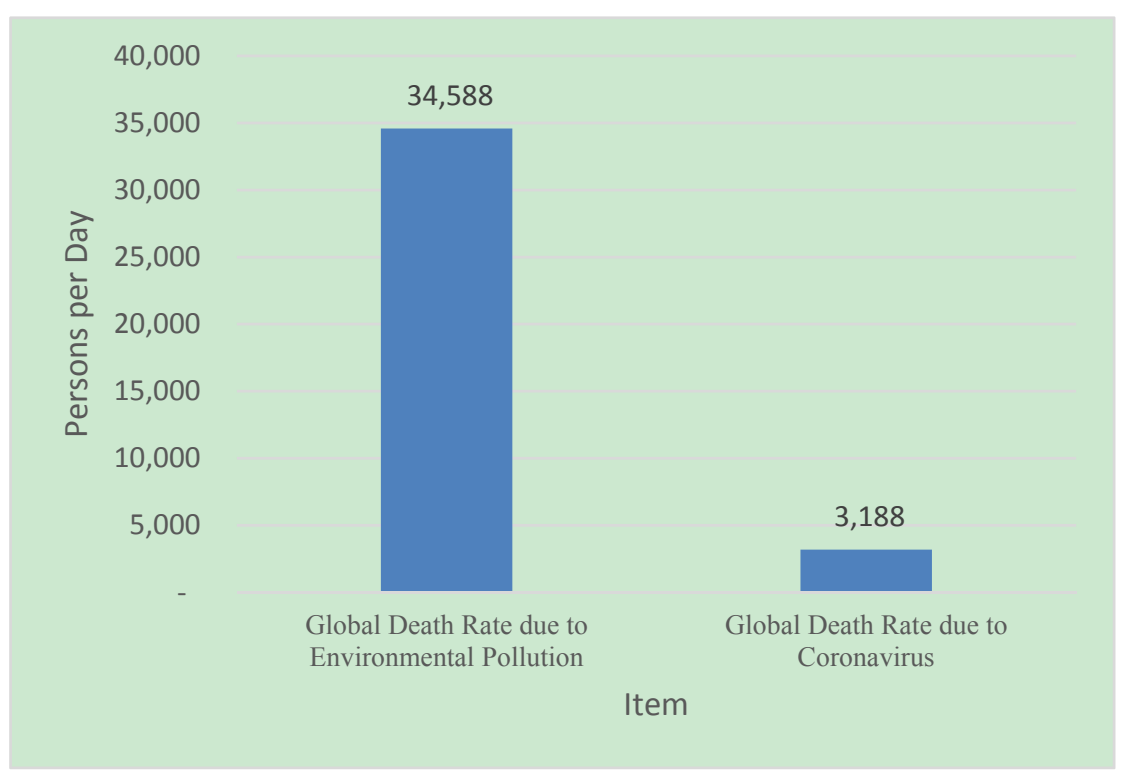

Figure 4. Global death rate (Persons/day)

Source: Drawn by author

The statistical models developed will be reviewed after any large-scale intervention, if any such as development and application of medication.

Environmental problems and coronavirus problems are integral. The difference is that coronavirus is occurring within a shorter period of time, but environmental \& other problems are occurring for a long time. The root is the same. Therefore, offer the solution together.

The solution is easy and simple. Stop the generation of environmental problems. This would mean stop burning of fossil fuel. The problem will go. You will get a clean environment and everybody is saved.

But this important solution cannot be implemented. Human civilization is built on the application of fossil fuels. If burning of fossil fuels is stopped, the entire human civilization will stop. Can you do it? None can do it because building the civilization has come a long way. So, we must look for an alternative way.

The feasible way is treatment of the air emissions suitably before leaving in the atmosphere so that these do not create air pollutions and the emissions remain within the tolerable standards. This is possible and feasible. One important environmental program of the USA has achieved considerable success. This is US Clean Air Act. According to one progress report (USEPA, Aug 14, 2019), between 1990 and 2017, national concentrations of air pollutants improved 80 percent for lead, 77 percent for carbon monoxide, 88 percent for sulfur dioxide (1-hour), 56 percent for nitrogen dioxide (annual), and 22 percent for ozone. Gradual switching to improved technology is another option to go parallel.

Similar treatment to the water effluent must be enforced.

It will be as I have noted in some people, argued that the treatment system is expensive. Expensive and any other matter are not more important than the human lives in the world.

Gradual improvement of the air pollution is a feasible solution. Scientists should be up and doing to be faster in this respect.

Treatment of air emission and water effluent discharge before leaving to the environment is a must and without failure for the world. It is overdue.

\section{References}

Carbon Dioxide Information Analysis Center CDIAC: Global Carbon Project (GCP); Annual Total CO2 Emissions, by World Region. 
Miah, M. A. Q. (2017). Applied Statistics for Social and Management Sciences. Springer, Singapore. https://doi.org/10.1007/978-981-10-0401-8

National Academy of Sciences USA. (2007).

Primary Causes of Air Pollution. Retrieved from https://www.eartheclipse.com/pollution/primary-causes-of-airpollution.html

Ritchie, H., \& Roser, M. (2019). Air Pollution - Our World in Data.

Shin, J. Y. et al. (2006). Isolation and Characterization of Novel H3N1 Swine Influenza Viruses from Pigs with Respiratory Diseases in Korea. Journal of Clinical Microbiology, 44(11), 3923-27. https://doi.org/10.1128/JCM.00904-06

World Health Organization (WHO), Total Environment Attributable Deaths. (2012). Global Health Observatory (GHO) data.

World Health Organization. (n.d.). An estimated 12.6 million deaths each year are attributable to unhealthy environments.

World Health Organization. Retrieved from https:/energyfactor.exxonmobil.com/perspectives/

Worldometer COVID-19 Data, WORLDOMETER, COVID-19 Coronavirus Pandemic. Retrieved from https://www.worldometers.info

\section{Copyrights}

Copyright for this article is retained by the author(s), with first publication rights granted to the journal.

This is an open-access article distributed under the terms and conditions of the Creative Commons Attribution license (http://creativecommons.org/licenses/by/4.0/). 